\title{
Kenneth E. Salyer: Transforming Faces, Renewing Lives
}

\author{
Karoon Agrawal ${ }^{1}$ \\ ${ }^{1}$ Department of Plastic Surgery, National Heart Institute, New Delhi, \\ India
}

Indian J Plast Surg 2021;54:103-105.

A pioneer in craniofacial and cleft reconstructive surgery, Kenneth E Salyer ( - Fig. 1) had an illustrious career spanning more than half a century. He joined plastic surgery private practice in 1979. He was the first chairman of the department of plastic surgery at University of Texas South Western Medical School, and in 1986 he founded the International Craniofacial Institute and Cleft Lip and Palate Treatment Centre at Dallas, United States.

Dr Kenneth's contribution to craniofacial surgery is immense. He was truly an international ambassador. He performed more than 17,000 surgeries on patients from all over United States and more than 75 countries around the world. He established the World Craniofacial Foundation in 1989 which he dedicated to the care of children with craniofacial deformities all over the world.

He served as the president of International Society of Craniofacial Surgery, American Society of Maxillofacial Surgery, and American Society of Craniofacial Surgery, and as the chairman of the Plastic Surgery Research Council and the American Academy of Pediatric Section of Plastic Surgery. He had been a visiting professor at more than 50 medical schools around the world where he had received many accolades including degrees, memberships, and professorships. He was the recipient of a lifetime achievement award from Friends of the National Institute of Health.

Throughout his career, Dr Salyer remained an active researcher and writer. He has contributed over 200 peer-reviewed publications and chapters in books. He has also authored, coauthored, or edited 11 books. I am in proud possession of most of his publications which were gifted to me by Dr IT Jackson and one by Dr Salyer himself. The one which touched me the most was A Life That Matters: Transforming Faces, Renewing Lives, which he gave me during Cleft 2017 at Chennai, India, with his blessings in person (-Fig. 2).

I had been reading his research papers and watching his presentations right from the time of my residency. I learnt more about him during my training with Dr IT Jackson. I got

published online

June 29, 2021
DOI https://doi.org/

$10.1055 / \mathrm{s}-0041-1731259$ ISSN 0970-0358
Address for correspondence Karoon Agrawal, MS, MCh, E-44, Panchsheel Park, New Delhi 110017, India (e-mail: karoonaparna@gmail.com).

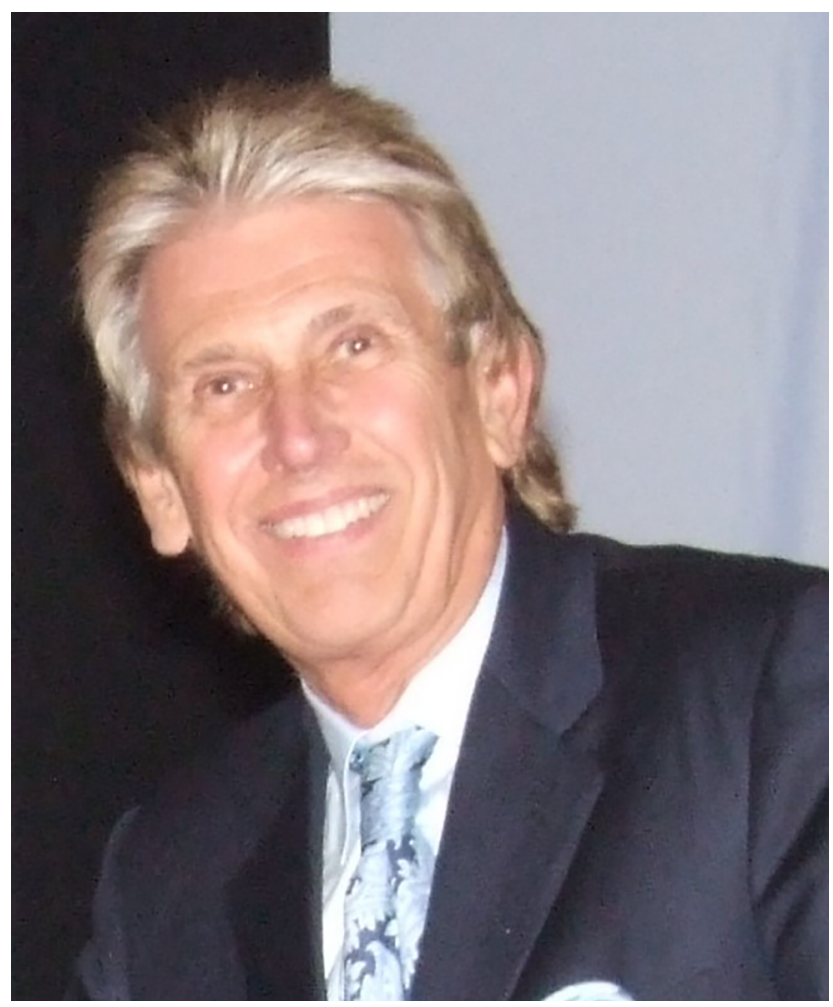

Fig. 1 Dr. Kenneth E. Salyer
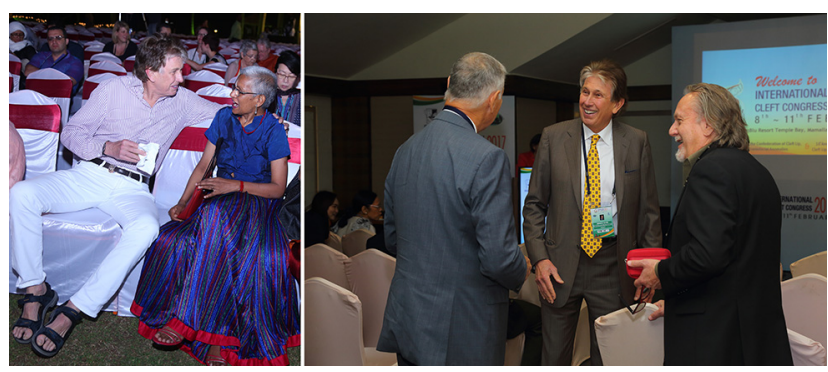

Fig. 2 Dr Salyer during Cleft 2017, Chennai, India. (a) With Dr Jyotsna Murthy, Organizing Chairperson, Cleft 2017. (b) With other delegates. (Photographs courtesy Dr Syed Altaf Hussain, Chennai, India).

(C) 2021. Association of Plastic Surgeons of India.

This is an open access article published by Thieme under the terms of the Creative Commons Attribution-NonDerivative-NonCommercial-License, permitting copying and reproduction so long as the original work is given appropriate credit. Contents may not be used for commercial purposes, or adapted, remixed, transformed or built upon. (https://creativecommons.org/licenses/by-nc-nd/4.0/).

Thieme Medical and Scientific Publishers Pvt. Ltd. A-12, 2nd Floor, Sector 2, Noida-201301 UP, India 
an opportunity to meet him in person during the 6th Asian Pacific Cleft Lip and Palate Congress organized at Panaji Goa, in 2007, where all the delegates were mesmerized by his inaugural keynote. He was addressing the full house of cleft surgeons, moving around inside the hall, and changing the slides with remote without watching the screen even once. Once his 45-minute address on cleft lip repair left the audience mesmerized with his results. We were awestruck with the long-term follow-up results of cleft lip repair and the cleft rhinoplasty. I was personally highly impressed with his perfection and his observations. Thereafter, he presented some of his craniofacial works which made me feel too small in front of this giant achiever ( - Fig. 3 ).

I was not fortunate enough to have any training under him and missed visiting Dallas a couple of times. However, I know few of my colleagues who have been trained by him and have very high regards for his teaching and training skills. However, I was fortunate enough to have met him many times over the past two decades at various cleft and craniofacial meetings. We last met during the 13th International Cleft Lip and Palate Foundation (ICPF) meeting at Nagoya, Japan, in July 2019. It was a chance that we were staying in the same hotel, and it gave an opportunity of leisure meetings in the lobby of the hotel. We shared the dais during one of the important sessions in the conference. He was chairperson for the session in which I was delivering the keynote. He was also the instructor and organizer along with Dr Akira Yamada for the Microtia Reconstruction Workshop" (-Fig. 4). Whenever I met Dr Salyer, I learnt a new technique and got encouragement to do better and better.

He was the greatest showman among all the plastic surgeons I have come across. He did his best to make things happen to his liking. During Cleft 2017 at Chennai we had a session together during one of the post-lunch sessions. We two were the only speakers in the session. He was supposed to speak before me. As it always happens, in spite of the best

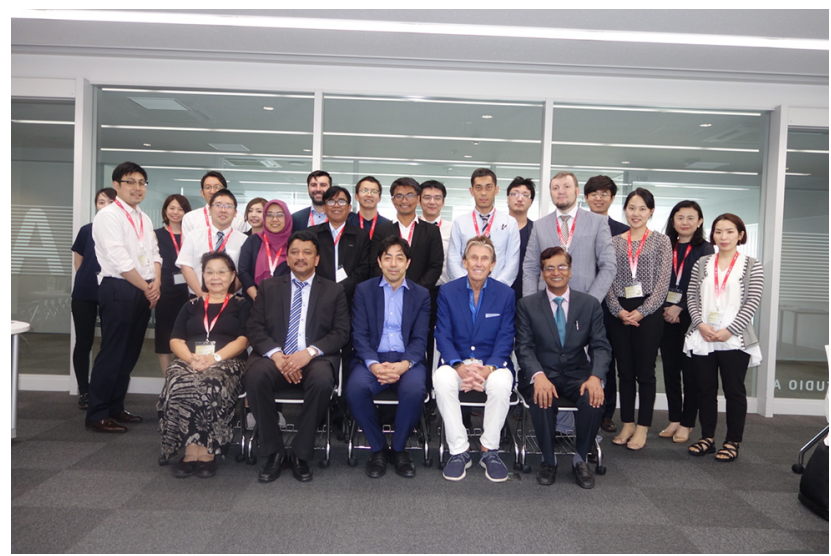

Fig. 4 Dr Ken Salyer with delegates attending the Microtia Workshop during ICPF conference, Nagoya, Japan, 2019.

efforts of the organizers, the post-lunch inertia kept the delegates away from the halls. Seeing a handful of delegates in the hall he asked me if I will mind starting the session which I agreed to and delivered my talk on difficult cleft palate repair. He followed my presentation, thank God by this time there were enough delegates inside the hall. Later, outside the hall he gifted me one of his creations with his personal note (-Fig. $\mathbf{5}$ ).

Dr Salyer was part of a generation of surgeons who were unique. They worked very hard, innovated, had great vision, and had the guts to do things which an average surgeon would never dare do. As a resident on neurosurgery rotation duty, he was one of the first attendees to President John F Kennedy at Parkland Hospital on the day of his assassination. He performed a successful miracle surgery by separating Egyptian craniopagus twins Ahmed and Mohamed with extraordinary planning and execution. He went beyond the realms of geographical boundaries. He not just reconstructed the defects and corrected the deformities but he had aesthetic
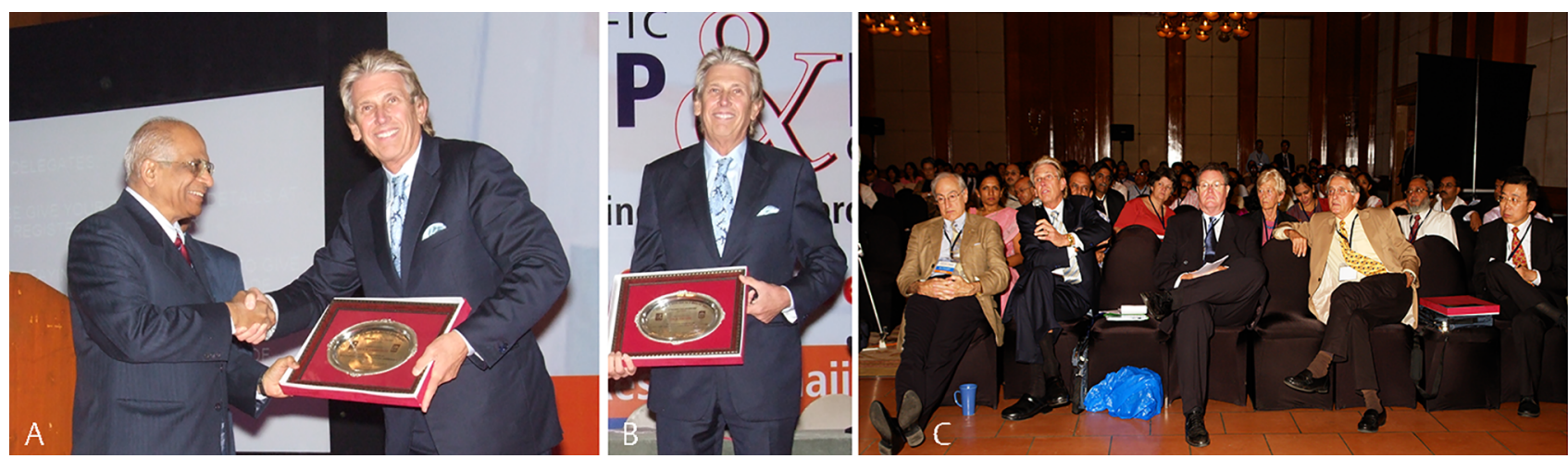

Fig. 3 Dr Kenneth Salyer at 6th Asia Pacific Cleft Congress at Panjim, Goa, in 2007. (a) Dr SR Tambwekar presenting a plaque, (b) Dr Salyer with the plaque, and (c) in the company of David David, David Precious, Ian T Jackson, and Philip Chen. (Photographs courtesy Dr Sanjeev Deshpande, Mumbai, India). 
Kenneth Salyer: Transforming Faces Agrawal

105

A Life That Matters

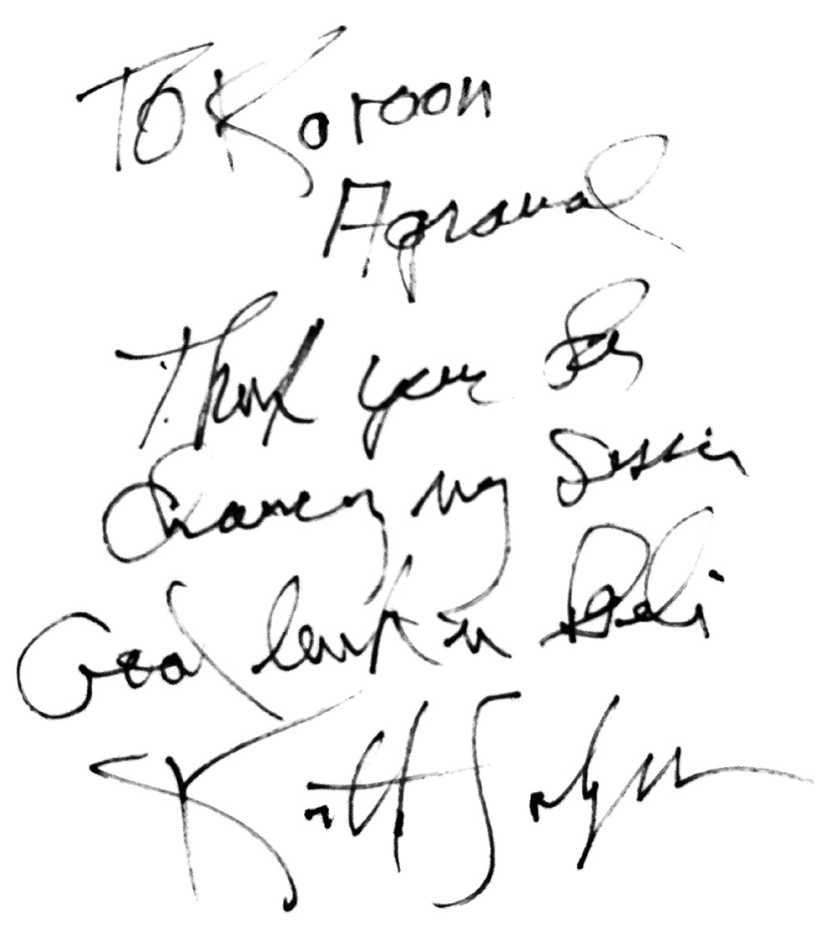

considerations in every surgery. It created aesthetic results beyond reproducibility.

After retirement, Dr Ken devoted himself to mission work through the World Craniofacial Foundation. He once said, "I grew increasingly determined to create a professional life that mattered-one in which I could be of service to mankind," and he justifiably did. What a wonderful life he led. With him ends an era of cleft and craniofacial surgery; however, the legacy continues. With due respect, I pray for the peaceful sojourn of his great soul to the heavenly abode.

Disclosures

No copyright or financial disclosures.

Conflict of interest

None declared.

Fig. 5 Personal note inscribed on the book A Life That Matters.

Indian Journal of Plastic Surgery Vol. 54 No. 2/2021 @ 2021. Association of Plastic Surgeons of India. 